\title{
Effects of Greek orthodox christian church fasting on serum lipids and obesity
}

\author{
Katerina O Sarri*, Nikolaos E Tzanakis, Manolis K Linardakis, \\ George D Mamalakis and Anthony G Kafatos
}

Address: Department of Social Medicine, University of Crete, School of Medicine, P.O Box 1393, Iraklion 71110, Crete, Greece

Email: Katerina O Sarri* - katsarri@med.uoc.gr; Nikolaos E Tzanakis - tzanakis@med.uoc.gr; Manolis K Linardakis - linman@med.uoc.gr; George D Mamalakis - geor40@yahoo.com; Anthony G Kafatos - kafatos@med.uoc.gr

* Corresponding author

Published: 16 May 2003

BMC Public Health 2003, 3:16
Received: 30 October 2002

Accepted: 16 May 2003

This article is available from: http://www.biomedcentral.com/I47/-2458/3/16

(c) 2003 Sarri et al; licensee BioMed Central Ltd. This is an Open Access article: verbatim copying and redistribution of this article are permitted in all media for any purpose, provided this notice is preserved along with the article's original URL.

\begin{abstract}
Background: No study to date has focused on the impact of Greek Orthodox Christian fasting on serum lipoproteins and obesity yet.

Methods: 120 Greek adults were followed longitudinally for one year. Sixty fasted regularly in all fasting periods (fasters) and 60 did not fast at all (controls). The three major fasting periods under study were: Christmas (40 days), Lent (48 days) and Assumption (August, I5 days). A total of 6 measurements were made during one year including pre- and end-fasting blood collection, serum lipoprotein analyses and anthropometric measurements.

Results: Statistically significant end-fasting total and LDL cholesterol differences were found in fasters. Fasters compared to controls presented $12.5 \%$ lower end-total cholesterol $(p<0.00 \mathrm{I})$, $15.9 \%$ lower end-LDL cholesterol $(p<0.00 \mathrm{I})$ and I.5\% lower end-BMI $(p<0.00 \mathrm{I})$. The end- LDL/ HDL ratio was lower in fasters $(6.5 \%, p<0.05)$ while the change in end- HDL cholesterol in fasters (4.6\% decline) was not significant. Similar results were found when the pre- and end-fasting values of fasters were compared. No change was found in control subjects.

Conclusions: Adherence to Greek Orthodox fasting periods contributes to a reduction in the blood lipid profile including a non-significant reduction in HDL cholesterol and possible impact on obesity.
\end{abstract}

\section{Background}

Fasting, the voluntary abstention from all restricted foods, is a feature of many religions, and the putative health benefits have attracted both scientific and popular interest. Commonly, religious doctrines proscribe foods from animal sources permanently or for particular periods.
There are several religions, such as Hinduism, Buddhism, Judaism, Islam, Seventh-Day-Adventism that have often been studied regarding their relation to health [1-14]. However, the studies on Orthodox Christianity are very limited. 
Orthodox Christian holy books recommend a total of 180-200 days of fasting per year. The faithful are advised to avoid olive oil, meat, fish, milk and dairy products every Wednesday and Friday throughout the year. Additionally, there are three principal fasting periods per year: i) a total of 40 days preceding Christmas (meat, dairy products and eggs are not allowed, while fish and olive oil are allowed except on Wednesdays and Fridays), ii) a period of 48 days preceding Easter (Lent). During Lent fish is allowed only two days whereas meat, dairy products and eggs are not allowed. Olive oil consumption is allowed only at weekends, iii) a total of 15 days in August (the Assumption) when the same dietary rules apply as for Lent with the exception of fish consumption which is allowed only on August $6^{\text {th }}$. Seafood such as shrimps, squid, cuttlefish, octopus, lobsters, crabs as well as snails are allowed on all fasting days throughout the year. The Greek Orthodox fasting practices can therefore be characterized as requiring a periodic vegetarian diet including fish and seafood.

The variant of vegetarianism followed during fasting periods by Orthodox Christians, with a diet of vegetables, legumes, nuts, fruits, olives, bread, snails and seafood, is a type of the so-called Mediterranean diet $[15,16]$. To date little is known as to the effects of this 'hidden' element of the traditional Orthodox Christian diet on health and no data exist on the effect of Orthodox Christianity's dietary rules on blood lipid levels and obesity. The objective of this study was therefore to assess the effects of intermittent short-term religious fasting, according to the dietary rules of the Orthodox Christian Church, on blood lipoprotein profile and the prevalence of obesity.

\section{Methods \\ Subjects}

The subjects of this study were selected from an adult population in the region of Heraklion, Crete. One hundredtwenty Orthodox Christians were asked to participate in this study. Sixty individuals (31 males, 29 females), mean age $(\mathrm{x} \pm \mathrm{SD}) 41 \pm 12$ years, fasted regularly according to the dietary rules and the fasting periods of the Christian Orthodox Church. Fasters had been practicing the fasting rituals for a mean of $20 \pm 14$ years. Another group of sixty subjects (24 males, 36 females), mean age $(x \pm S D) 38 \pm 9$ years, were control subjects that did not fast. Among the fasting group, 20 were lay persons (fasted for $13 \pm 10$ years) and 40 were under religious order (fasted for $23 \pm$ 15 years): 19 nuns living in a convent and 21 priests living with their families in community parishes. The family history of each subject was recorded with regard to diabetes, CHD, smoking, hormonal disturbances and drug intake.

\section{Study design}

Three pairs of measurements were made over a 1-year period (2000-2001), coinciding with the beginning and end of each of the three major fasting periods of the Christian Orthodox Church: Christmas, Lent and the Assumption. All measurements were made between 8.00-10.00 am and they included fasting blood collection, anthropometric measurements and the completion of questionnaires.

\section{Questionnaires}

All subjects signed informed consent forms and completed questionnaires on fasting, health habits (coffee and alcohol consumption, smoking), certain items of personal data (marital status, educational level), physical activity, dietary habits (24 h recall, 3-day dietary record). Fasters were defined as those who fasted regularly during all three principal fasting periods, while current smokers as those who smoked at least one cigarette per day.

\section{Anthropometric variables}

Body weight was measured all six times by a digital scale (Seca, Hamburg, Germany, Model 770) with an accuracy of $\pm 100 \mathrm{~g}$. Subjects were weighed barefoot in very light clothing. Standing height was measured once without shoes to the nearest $0.5 \mathrm{~cm}$ with the use of a stadiometer with the shoulders in relaxed position and arms hanging freely. Body Mass Index (BMI) was calculated by dividing weight $(\mathrm{kg})$ by height squared $\left(\mathrm{m}^{2}\right)$. Waist and hip circumferences were measured twice, at the first and sixth measurement of the study [17]. Blood pressure (BP) was measured all six times in the right arm with a traditional sphygmomanometer. Three seated BP measurements were taken for each subject spaced two minutes apart.

\section{Biochemical assays}

Serum lipoprotein concentrations were always determined after $12 \mathrm{~h}$ of fasting. Blood samples were transferred to the University hospital of Crete in tanks containing ice packs that maintained the temperature at $3-4^{\circ} \mathrm{C}$. Total cholesterol was determined by Allain's method [18], HDL-C was measured by the heparin-manganese precipitation method [19] and triacylglycerols were determined using Fossati's method [20], while LDL$\mathrm{C}$ was calculated as follows: LDL-C $=\mathrm{TC}-(\mathrm{HDL}-\mathrm{C}+\mathrm{TG} /$ 5) [21]. During the period October 2000 - September 2001 the coefficient of variation for the biochemical analysis of total cholesterol was 2,85\%, for HDL was 5,40\% and for triacylglycerols was $3,92 \%$. DNA extraction was performed according to the method of Miller et al [22]. Apo E genotype was determined by PCR amplification and subsequent digestion with the restriction enzyme Hha I (New England Biolabs) as described by Reymer et al [23] in Harokopio University of Athens. 
Table I: Sociodemographic characteristics of the population.

\begin{tabular}{|c|c|c|c|}
\hline & $\begin{array}{l}\text { FASTERS } \\
N(\%)\end{array}$ & $\begin{array}{l}\text { CONTROLS } \\
\mathrm{n}(\%)\end{array}$ & $\mathrm{P}$ \\
\hline \multicolumn{4}{|l|}{ Sex } \\
\hline Males & $31(52 \%)$ & $24(40 \%)$ & NSa \\
\hline Females & $29(48 \%)$ & $36(60 \%)$ & \\
\hline Age (years) ${ }^{c}$ & $42 \pm 12$ & $38 \pm 9$ & NSb \\
\hline \multicolumn{4}{|l|}{ Tobacco use } \\
\hline Smokers & $4(7 \%)$ & $33(55 \%)$ & $<\left.0.00\right|^{a}$ \\
\hline Non-smokers & $56(93 \%)$ & $27(45 \%)$ & \\
\hline \multicolumn{4}{|l|}{ Educational level } \\
\hline Higher & $26(43 \%)$ & $14(23 \%)$ & NSa \\
\hline Secondary & $24(40 \%)$ & $34(57 \%)$ & \\
\hline Minimum school level / No education & $10(17 \%)$ & $12(20 \%)$ & \\
\hline
\end{tabular}

a. Chi-square test $\left(\chi^{2}\right)-$ Fisher exact test. b. ANOVA analysis. c. Values are means $\pm S D$.

\section{Statistical methods}

Differences in gender, tobacco use, educational level and apolipoprotein E distribution were compared using $\chi^{2}$ analysis, while differences in age were compared by ANOVA analysis. Regression analysis was used to compare endfasting lipid concentrations and BMI with age, sex, smoking, educational level, BMI, WHR, fasting and the pre-fasting values. The influence of fasting on end-fasting values was examined using ANCOVA analysis. Paired samples Ttest and Mann-Whitney test were used to compare pre and end-fasting values in fasters.

Pre-fasting values comprise the mean of the three measurements that were made before the beginning of the Christmas, Lent and Assumption fasting periods, while end-fasting values are the mean of the three measurements that were made at the end of each one of the fasting periods.

\section{Results}

Demographic data on a hundred and twenty subjects are presented in Table 1. Sixty of the subjects were fasters (26\% male, $24 \%$ female) with a mean age of $42 \pm 12$; the other sixty were control subjects (20\% male, 30\% female) with a mean age of $38 \pm 9$. There was no statistically significant difference in the age of the two groups (ANOVA). The subjects in the fasters group had been observing the fasting rituals for a mean of $20 \pm 14$ years. The rate of compliance with the fasting rules was $100 \%$. All subjects in both groups did not suffer from any disease like thyroid, diabetes, cancer, cardiovascular diseases, and did not take any medication.

The levels of serum lipids, blood pressure and body measurements of all three periods for fasters and controls are presented in table 2 .

\section{Effect of fasting on end-fasting values}

Multiple Linear Stepwise Regression Analysis indicated that fasting is a significant determinant for end-total cholesterol, end-LDL cholesterol, end-LDL/HDL ratio and end-BMI (Table 3), showing that fasters have lower levels of these variables.

Females have higher levels of end-HDL cholesterol while men have higher levels of end-TC/HDL and end-LDL/ HDL ratios. Waist-to-hip ratio was positively related to end-total cholesterol and end-LDL cholesterol.

\section{Comparisons of end-fasting values between the two groups} Comparisons of mean end-fasting values between fasters and controls are shown in Table 4. Mean end-TC, endLDL and end-BMI were statistically lower $(\mathrm{p}<0.001)$ in fasters compared to controls. Fasters presented $12.5 \%$ lower end-TC, $15.9 \%$ lower end-LDL cholesterol and $1.5 \%$ lower end-BMI compared to controls. Moreover, fasters had significantly lower LDL/HDL ratios ( $\mathrm{p}<0.05)$. All results were adjusted for age, sex, BMI and smoking.

\section{Comparisons of pre and end-fasting values in the fasters' group}

The fasters who had 3 complete pairs of measurements were included in this analysis (Table 5). Paired samples Ttest showed that fasters presented $9.1 \%$ decline in end- total cholesterol, $12.4 \%$ decline in end- LDL, 8.5\% decline in end- HDL and $1.4 \%$ decline in end- BMI compared to their respective pre-values. All these differences were significant $(\mathrm{p}<0.001)$. As for the ratios end- TC/HDL and end- LDL/HDL although they declined the changes were not significant. The same analysis was done in controls that presented no significant changes over the year. A further step was to categorize fasters in two subgroups: 1) nun-priests and 2) lay people and to compare their preand end- fasting values. Mann-Whitney test showed that 
Table 2: Levels of serum lipids, blood pressure and body measurements.

\begin{tabular}{|c|c|c|c|c|c|c|c|}
\hline & & \multicolumn{2}{|c|}{ CHRISTMAS } & \multicolumn{2}{|c|}{ EASTER } & \multicolumn{2}{|c|}{ AUGUST } \\
\hline & & PRE-a & END-a & PRE-a & END-a & PRE-a & END-a \\
\hline \multirow[t]{2}{*}{ GLUCOSE (mmol/L) } & $\mathrm{Fb}^{\mathrm{b}}$ & $4.97 \pm 1.24(59)$ & $4.97 \pm 1.39(56)$ & $4.65 \pm 0.88(49)$ & $4.85 \pm 1.13(52)$ & $5.16 \pm 1.15(47)$ & $4.91 \pm 1.11(48)$ \\
\hline & $\mathrm{Cb}^{\mathrm{b}}$ & $4.75 \pm 0.73(60)$ & $5.00 \pm 1.25(52)$ & $4.76 \pm 1.00(54)$ & $4.48 \pm 0.68(50)$ & $4.62 \pm 0.69(4 I)$ & $4.73 \pm 0.87(43)$ \\
\hline \multirow[t]{2}{*}{ TCHOL (mmol/L) } & $\mathrm{F}$ & $5.90 \pm 1.20(59)$ & $5.45 \pm 1.13(56)$ & $5.63 \pm 1.15(49)$ & $5.05 \pm 1.15(52)$ & $5.51 \pm 1.17(47)$ & $5.12 \pm 1.18(48)$ \\
\hline & C & $5.25 \pm 1.02(60)$ & $5.24 \pm 1.12(52)$ & $5.25 \pm 1.09(54)$ & $5.08 \pm 1.04(50)$ & $5.16 \pm 1.02(4 I)$ & $5.48 \pm 1.28(43)$ \\
\hline \multirow[t]{2}{*}{ HDL (mmol/L) } & $\mathrm{F}$ & $1.22 \pm 0.35(59)$ & $1.19 \pm 0.27(56)$ & $1.17 \pm 0.33(49)$ & $1.05 \pm 0.29(52)$ & $1.23 \pm 0.60$ & $1.09 \pm 0.28(48)$ \\
\hline & C & $1.18 \pm 0.28(60)$ & $1.21 \pm 0.28(52)$ & $1.36 \pm 0.78$ & $1.19 \pm 0.29(50)$ & $\mathrm{I} .20 \pm 0.28(4 \mathrm{I})$ & $1.20 \pm 0.33$ \\
\hline \multirow[t]{2}{*}{ TRIGL (mmol/L) } & $\mathrm{F}$ & $1.48 \pm 0.95(59)$ & $1.39 \pm 0.81(56)$ & $1.38 \pm 0.72(48)$ & $1.43 \pm 0.92(52)$ & $1.31 \pm 0.82(47)$ & $1.36 \pm 0.90(48)$ \\
\hline & C & $1.01 \pm 0.42(60)$ & $1.02 \pm 0.50(52)$ & $1.04 \pm 0.42$ & & & \\
\hline \multirow[t]{2}{*}{ LDL (mmol/L) } & $\mathrm{F}$ & $4.00 \pm 1.06(59)$ & $3.62 \pm 1.00(56)$ & $3.80 \pm 0.99(48)$ & $3.33 \pm 0.97(5 \mathrm{I})$ & $3.75 \pm 1.03(47)$ & $3.41 \pm 1.05(48)$ \\
\hline & C & $3.61 \pm 0.91(60)$ & $3.56 \pm 1.01(52)$ & $3.58 \pm 0.99(54)$ & $3.37 \pm 0.95(50)$ & $3.47 \pm 0.94(40)$ & $3.77 \pm 1.13(43)$ \\
\hline \multirow[t]{2}{*}{ TC_HDL } & $\mathrm{F}$ & $5.21 \pm 1.80(59)$ & $4.81 \pm 1.48(56)$ & $5.10 \pm 1.49(49)$ & $5.14 \pm 1.71(52)$ & $5.04 \pm 1.73(47)$ & $4.97 \pm 1.54(48)$ \\
\hline & C & $4.70 \pm 1.44(60)$ & $4.58 \pm 1.50(52)$ & $4.37 \pm 1.52(54)$ & $4.48 \pm 1.35(50)$ & $4.52 \pm I .37(4 I)$ & $4.79 \pm 1.42(43)$ \\
\hline \multirow[t]{2}{*}{ WEIGHT (kg) } & $\mathrm{F}$ & $78.4 \pm 16.4(60)$ & $77.0 \pm 16.0(57)$ & $77.6 \pm 16.0(51)$ & $76.0 \pm 15.5(52)$ & $76.4 \pm 16.1$ (47) & $75.4 \pm 15.7$ (49) \\
\hline & C & $72.3 \pm 15.8(60)$ & $74.1 \pm 16.4(52)$ & $73.1 \pm 16.2(54)$ & $72.7 \pm 16.5(50)$ & $74.1 \pm 17.0(4 I)$ & $74.7 \pm 16.6(43)$ \\
\hline \multirow[t]{2}{*}{ BMI $\left(\mathrm{kg} / \mathrm{m}^{2}\right)$} & $\mathrm{F}$ & $28.6 \pm 5.1(59)$ & $28.3 \pm 5.1(57)$ & $28.2 \pm 4.7(5 \mathrm{I})$ & $27.7 \pm 4.8(52)$ & $27.7 \pm 4.9(47)$ & $27.5 \pm 4.7(49)$ \\
\hline & C & $25.8 \pm 4.3(60)$ & $26.3 \pm 4.5(52)$ & $25.9 \pm 4.2(54)$ & $25.7 \pm 4.4(50)$ & $26 . I \pm 4.6(4 I)$ & $26.5 \pm 4.8(43)$ \\
\hline \multirow[t]{2}{*}{ SYST (mm Hg) } & $\mathrm{F}$ & $129 \pm 18(59)$ & $128 \pm 19(57)$ & $|30 \pm 2|(5 \mid)$ & $129 \pm 20(52)$ & $121 \pm 16(47)$ & $117 \pm 16(49)$ \\
\hline & C & $117 \pm 14(60)$ & $109 \pm 12(52)$ & $109 \pm 13(53)$ & $106 \pm 13(50)$ & $106 \pm 15(41)$ & $107 \pm 12(43)$ \\
\hline \multirow[t]{2}{*}{ DIAST (mm Hg) } & $\mathrm{F}$ & $79 \pm 8(59)$ & $79 \pm 13(57)$ & $79 \pm 13(5 \mathrm{I})$ & $81 \pm 13(52)$ & $77 \pm 12(47)$ & $73 \pm 10(49)$ \\
\hline & C & $74 \pm 11(60)$ & $69 \pm 9(52)$ & $67 \pm 10(53)$ & $67 \pm 9(50)$ & $66 \pm 11(4 I)$ & $66 \pm 10(43)$ \\
\hline
\end{tabular}

a. The values are presented as Mean $\pm S D(n)$ b. $F=$ Fasters, $C=$ Controls

Table 3: Effect of various variables including fasting on serum lipids and BMI.a

\begin{tabular}{|c|c|c|c|c|}
\hline Dependent variables & Predictors & Beta & $\mathbf{t}$ & $\mathbf{p}$ \\
\hline \multirow[t]{4}{*}{ End Total Cholesterol } & Pre-fasting TC & 0.94 & 28.3 & $<0.001$ \\
\hline & Fasting & -0.24 & -7.7 & $<0.001$ \\
\hline & WHR & 0.19 & 3.2 & 0.002 \\
\hline & Sex & -0.12 & -2.1 & 0.037 \\
\hline \multirow[t]{4}{*}{ End LDL cholesterol } & Pre-fasting LDL-C & 0.93 & 32.7 & $<0.001$ \\
\hline & Fasting & -0.23 & -8.5 & $<0.001$ \\
\hline & WHR & 0.2 & 3.9 & $<0.001$ \\
\hline & Sex & -0.12 & -2.4 & 0.018 \\
\hline \multirow[t]{2}{*}{ End HDL cholesterol } & Pre-fasting HDL-C & 0.74 & 10.9 & $<0.001$ \\
\hline & Sex & -0.24 & -3.54 & $<0.001$ \\
\hline \multirow[t]{2}{*}{ End TC/HDL cholesterol } & Pre TC:HDL-C & 0.85 & 19.1 & $<0.001$ \\
\hline & Sex & 0.17 & 3.9 & $<0.001$ \\
\hline \multirow[t]{3}{*}{ End LDL/HDL cholesterol } & Pre LDL:HDL-C & 0.88 & 21.0 & $<0.001$ \\
\hline & Sex & 0.14 & 3.4 & $<0.001$ \\
\hline & Fasting & -0.1 & -2.7 & 0.008 \\
\hline \multirow[t]{2}{*}{ End fasting BMI } & Pre-fasting BMI & 1.0 & 115.9 & $<0.001$ \\
\hline & Fasting & -0.35 & -4.06 & $<0.001$ \\
\hline
\end{tabular}

Multiple Linear Stepwise Regression Analysis with mean end-TC, end-LDL cholesterol, end-HDL cholesterol, end-BMI and the end-ratios of TC/ HDL-C and LDL-C/HDL-C as the dependent variables. Independent variables were age, mean pre-BMI, fasting, smoking, sex, educational level, WHR, pre-ratios of TC/HDL-C and LDL-C/HDL-C and the pre-values of the dependent variables. Sex, fasting and smoking are dummies (sex: $0=$ females and $\mathrm{I}=$ males, fasting: $0=$ control subjects and $\mathrm{I}=$ fasters, smoking: $0=$ smokers and $\mathrm{I}=$ non-smokers). a. The subjects that had all six measurements were included $(n=7 I)$. 
Table 4: ANCOVA analysis. Effect of fasting on end-fasting mean ratios with covariates the respective pre-fasting mean ratios between fasters and control subjects.

\begin{tabular}{|c|c|c|c|c|c|}
\hline \multirow[t]{2}{*}{ End-fasting variables } & \multicolumn{2}{|c|}{ FASTERS $(n=40)$} & \multicolumn{3}{|c|}{ CONTROLS $(n=31)$} \\
\hline & Mean & SEMa & Mean & SEMa & $P$ \\
\hline Glucose (mmol/L) & 4.95 & 0.07 & 4.86 & 0.08 & NS \\
\hline Total cholesterol (mmol/L) & 4.9 & 0.05 & 5.6 & 0.06 & $<0.001$ \\
\hline HDL cholesterol (mmol/L) & I.I & 0.03 & 1.2 & 0.03 & NS \\
\hline LDL cholesterol (mmol/L) & 3.3 & 0.04 & 3.8 & 0.05 & $<0.001$ \\
\hline Triglycerides (mmol/L) & 1.27 & 0.05 & 1.25 & 0.06 & NS \\
\hline $\mathrm{TC} / \mathrm{HDL}-\mathrm{C}^{\mathrm{b}}$ & 4.7 & 0.08 & 5.0 & 0.1 & NS \\
\hline LDL-C/HDL-Cc & 3.1 & 0.06 & 3.3 & 0.07 & 0.041 \\
\hline BMI $\left(\mathrm{kg} / \mathrm{m}^{2}\right)$ & 27.0 & 0.06 & 27.4 & 0.07 & $<0.001$ \\
\hline
\end{tabular}

a. Standard Error of the Mean b. The ratio of total cholesterol: high-density lipoprotein c. The ratio of low-density lipoprotein: high-density lipoprotein The results are adjusted for age, BMI, sex, smoking

Table 5: Pared samples T-test. Mean pre-fasting values compared to mean end-fasting values in the group of fasters $(n=43)$.

\begin{tabular}{llllll}
\hline Variables & Pre-Fasting & & End-Fasting & \\
\cline { 2 - 6 } & Mean & SEMa & Mean & SEMa & P \\
\hline Glucose (mmol/L) & 4.93 & 0.16 & 4.95 & 0.19 & $\mathrm{NS}$ \\
Total cholesterol (mmol/L) & 5.6 & 0.15 & 5.1 & 0.14 & $<0.001$ \\
HDL cholesterol (mmol/L) & 1.2 & 0.04 & 1.1 & 0.04 & $<.13$ \\
LDL cholesterol (mmol/L) & 3.8 & 1.14 & 3.3 & 0.09 & NS \\
Triglycerides (mmol/L) & 1.41 & 0.13 & 1.36 & 0.2 & NS \\
TC/HDL-Cb & 5.0 & 0.2 & 4.9 & 0.1 & NS \\
LDL-C/HDL-Cc & 3.3 & 0.1 & 3.2 & 0.7 & $<0.001$
\end{tabular}

a. Standard Error of the Mean b. The ratio of total cholesterol: high-density lipoprotein c. The ratio of low-density lipoprotein: high-density lipoprotein

the changes seen in fasters' group remained when each subgroup was analyzed separately though they were not significant. It was observed that between the major fasting periods studied (between the end of Christmas and the beginning of Lent; and between the end of Lent and the beginning of the Assumption fasting period) when fasters returned to their usual dietary habits (non-fasting periods) total cholesterol and LDL cholesterol were increased by $6 \%$ and $9 \%$ respectively.

\section{Dietary data}

Table 6 shows that at end-fasting periods fasters had 10\% reduction in energy intake (EI), $17 \%$ reduction in total fat (\%EI), 23\% increase in carbohydrates (\%EI) and 43.5\% increase in fiber consumption, whereas the respective percentages for the controls are $+7 \%,+1 \%,+1.7 \%$ and $+3.3 \%$. All the differences found between the two groups are significant.

\section{Distribution of Apo E polymorphism}

Subjects in this study were screened for the common apolipoprotein E (apoE) polymorphism, as genetic variation at the apoE locus has been shown to influence serum lipid responsiveness to dietary interventions and account for much of the interindividual variability in dietary response $[24,25]$ Several studies, for example, support the concept that the $\varepsilon 4$ allele is associated with an increased cholesterol response to dietary manipulation, and that subjects carrying the $\varepsilon 4$ allele are the most responsive to diets restricted in saturated fat and cholesterol [24-27].

Fasters and control subjects were classified in three groups according to their apoE genotype: subjects homozygous for the common 83 allele (apoE3/3 genotype, (38 fasters and 40 controls); subjects with the apoE2/3 genotype (nine fasters and four controls); carriers of the $\varepsilon 4$ allele (apoE3/4 and apoE4/4 genotypes; four fasters and six 
Table 6: Ancova analysis. Dietary differences between fasters and controls among pre and end-fasting periods based on the $24 \mathrm{~h}$ dietary record.

\begin{tabular}{|c|c|c|c|c|c|}
\hline & & Pre-fasting & End-fasting & Difference & $\mathrm{P}$-value \\
\hline & & \multicolumn{3}{|c|}{ Mean \pm SE } & \\
\hline \multirow[t]{2}{*}{ Energy (kcal) } & $\mathrm{Fa}$ & $1788 \pm 74$ & $1596 \pm 64$ & $-182 \pm 67$ & 0.002 \\
\hline & $\mathrm{Ca}^{\mathrm{a}}$ & $1906 \pm 75$ & $2043 \pm 65$ & $137 \pm 69$ & \\
\hline \multirow[t]{2}{*}{ Total fat (\% of total energy intake) } & $\mathrm{F}$ & $38.3 \pm 0.8$ & $31.8 \pm 1.1$ & $-6.6 \pm 1.1$ & $<0.001$ \\
\hline & C & $38.7 \pm 0.8$ & $39.1 \pm 1.1$ & $0.4 \pm 1.1$ & \\
\hline \multirow[t]{2}{*}{ Carbohydrates (\% of total energy intake) } & $\mathrm{F}$ & $48.8 \pm 1.1$ & $59.8 \pm 1.2$ & $11.0 \pm 1.3$ & $<0.001$ \\
\hline & C & $45.5 \pm 1.1$ & $44.6 \pm 1.3$ & $-0.8 \pm 1.3$ & \\
\hline \multirow[t]{2}{*}{ Protein (\% of total energy intake) } & $\mathrm{F}$ & $13.8 \pm 0.4$ & $10.0 \pm 0.4$ & $-3.8 \pm 0.6$ & $<0.001$ \\
\hline & C & $14.3 \pm 0.4$ & $14.4 \pm 0.4$ & $0.1 \pm 0.6$ & \\
\hline \multirow[t]{2}{*}{ Fiber (g per $1000 \mathrm{kcal})$} & $\mathrm{F}$ & $11.5 \pm 0.5$ & $16.5 \pm 0.5$ & $5.0 \pm 0.6$ & $<0.001$ \\
\hline & C & $9.2 \pm 0.5$ & $9.5 \pm 0.5$ & $0.3 \pm 0.6$ & \\
\hline
\end{tabular}

a. a. $F=$ Fasters $(n=58), C=$ Controls $(n=56)$ The results were adjusted for sex, age and pre-BMI. In the analysis were included the subjects that had completed the $24 \mathrm{~h}$ dietary record in all 6 measurements.

controls, respectively). Chi-square analysis showed that apoE genotype distribution did not differ between fasters and controls (data not shown).

\section{Discussion}

The most important finding of this study is that most serum lipid variables decreased significantly over the fasting periods. Fasters, as compared to controls, had decreased levels of mean end- total cholesterol, LDL-C, LDL/HDL-C ratio and BMI. Several genetic factors account for the variation in cholesterol levels and obesity indices, however, we believe that the possibilities of genetic differences between the two groups are minimal since the population of Crete is stable with a long history over 4000 years. In addition to this, the ApoE genotype distribution found no differences between the two groups (fasters vs controls). In the fasters' group the mean decrease within all three fasting periods was $9 \%$ for total cholesterol and $12 \%$ for LDL-C. However, it was observed that during non-fasting periods when fasters returned to their usual dietary habits, total cholesterol and LDL-C increased by $6 \%$ and $9 \%$ respectively. This shows that the reduced end-total and LDL cholesterol concentrations that were observed within the fasting periods were not sustained when the subjects returned to their usual dietary habits even though the increase did not reach the initial pre- levels. The reduction in HDL that occurred in fasters is a common finding with low-fat and vegetarian diets [28-31]. The findings above are in agreement with the results reported by Barnard et al who conducted a strict vegetarian-diet intervention study for 5 weeks on 35 women [30]. The intervention diet consisted of grains, legumes, vegetables and fruit. After the intervention diet phase total cholesterol, LDL and HDL were decreased by $13.2 \%, 16.9 \%$ and $16.5 \%$ respectively [30]. BMI was also significantly reduced $(\mathrm{p}<0.001)$ while, in agreement with our findings, the TC/HDL and LDL/HDL ratios remained unchanged (table 5)[30]. Similar were the findings in another 6-week vegetarian-diet intervention study by Masarei et al [28] and in a 12-week low-fat-vegan-diet intervention study by Nicholson et al [32]. Lee [33] and Hoffman [34], who compared omnivores with lacto-ovo-vegetarians, found no difference in LDL/HDL ratio between the two groups. The contrasting results on LDL/HDL ratio could be attributed to differences in the population samples studied.

Nieman et al [14] and Toohey et al [35] investigated Seventh-Day Adventists with similar demographic and lifestyle factors and with comparable diets and dietary habits to our cohort. They found that lacto-ovo-vegetarians and lifetime strict vegetarians had lower concentrations of total and LDL cholesterol when compared with non-vegetarians and lacto-ovo-vegetarians respectively $(\mathrm{p}<0.05)$ [14]. Toohey et al found also found lower levels of BMI, triacylglycerols and TC/HDL ratio [35]. The present study showed that women had lower levels of LDL/HDL ratio and TC/HDL ratio, which is also a better predictor for CHD in women [36-38]. This is explained by the higher concentrations of HDL that women have compared to men [39].

The positive association of waist-to-hip ratio with total and LDL cholesterol is in agreement with other studies that correlate waist-to-hip ratio with coronary risk factors and CHD prevalence [40-42]. Waist-to-hip ratio measurement is a simple and cost-effective measure that contributes in predicting abnormal lipoprotein levels and increased risk of cardiovascular disease. 
Both the fasting and control groups had mean BMI in the overweight category. Fasting had a small but statistically significant impact on fasters' BMI at the end of the fasting periods that was not sustained in non-fasting periods. In accordance to the results in this study, Haddad et al studying a group of vegans and nonvegetarians found significantly lower BMI levels in the vegan group [43]. Moreover, others found that vegetarians have lower BMI than meat eaters [44-46]. At the same time following a Mediterranean-style diet has also been proven to be beneficial to weight loss [47]. As regards religious fasting some studies associate it with weight loss and decline in BMI $[2,3]$ while others do not $[4,5,48]$.

Educational level was not found to influence any of the blood lipid variables in this study (Table 3). This was an unexpected result since higher education is associated with better health care and awareness whereas low educational level has been related to unfavorable lipid profile [49], all-cause and CAD mortality [50] and hypertension [51].

The beneficial changes seen in fasters diet during the fasting periods, especially regarding energy intake, total fat and fiber consumption, can also explain the reductions in the biochemical and obesity indices. A recent study of the University of Crete showed that the Christian Orthodox nuns' diet was very low in cholesterol and in saturated fat intake ( $6 \%$ of total energy intake), and high in fiber and antioxidant vitamins [16]. This could be attributed to nuns' high consumption of fruit, vegetables, cereals and legumes. In another study Haddad et al found that vegans consume more grains, vegetables, fruit, legumes and seeds and as a result their diet consists of more dietary fiber and less dietary cholesterol [43]. It is well known that reduced intakes of dietary SFA and cholesterol lower total and LDL cholesterol concentration and are associated with low risk of cardiovascular diseases [52,53]. The Orthodox Christians' diet, which is based on vegetables, legumes, fruit, cereals, bread and olive oil, is a Mediterranean-type of diet with periodic abstinence from meat and other animal products during the fasting periods. Numerous investigators [54-56] have recognized the beneficial role of the Mediterranean diet in cardiovascular diseases, and the protective effect in terms of cancer and longevity have also been noted $[57,58]$. In addition, supplementary studies have associated religiosity with good health [10]. This has been confirmed in a recent study by Chliaoutakis et al [59], which is the only published work to date which investigates the association between the Orthodox Christian lifestyle and health. Chliaoutakis et al found that devout Orthodox Christians adopt healthier life-styles and that religion has a substantial impact on mental and physical health-related behaviors [59]. In the present study, contrary to Chliaoutakis' findings, the physical activity of the two groups (fasters vs controls) did not differ in any of the testing periods.

Our study attempts to provide an understanding of the impact of Christian Orthodox fasting on serum blood lipids and obesity indices before and at the end of the three major fasting periods. Compared to controls, fasters presented decreased lipoproteins and BMI levels. These results support our hypothesis by highlighting the beneficial influence of Christian Orthodox fasting on lipoprotein profile and prevalence of obesity.

\section{Competing interests \\ None declared.}

\section{Authors' contributions}

Author K.S mainly organized and performed the study, and drafted the manuscript. Author N.T participated in the design of the study and supervised the manuscript. Author M.L performed the statistical analyses. Author G.M performed part of the statistical analysis. Author A.K conceived of the study, participated in its design, and supervised the study and the manuscript.

\section{Acknowledgments}

We appreciate the assistance of Bishop Nektarios of Crete in supporting the study and the Monasteries of Sabbathiana, Isodia Theotokou and Kremaston for their participation. We are also grateful to Dr N.Yiannakouris, Mrs C.Codrington, $\mathrm{Dr}$ C.Hatzis, Ms F.Bervanaki, Mr M.Kiriakakis and $\mathrm{Mr}$ G.Tsibinos.

\section{References}

I. Shatenstein B and Ghadirian P Influences on diet, health behaviours and their outcome in select ethnocultural and religious groups Nutrition 1998, 14(2):223-30

2. Temizhan A The effects of Ramadan fasting on blood lipid levels Am J Med 2000, 109(4):34I-2

3. Adlouni A Fasting during Ramadan induces a marked increase in high-density lipoprotein cholesterol and decrease in lowdensity lipoprotein cholesterol Ann Nutr Metab 1997, 4 I (4):2429

4. Maislos M Marked increase in plasma high-density-lipoprotein cholesterol after prolonged fasting during Ramadan Am J Clin Nutr 1993, 57(5):640-2

5. Maislos M Gorging and plasma HDL-cholesterol - the Ramadan model Eur J Clin Nutr 1998, 52(2): 127-30

6. Akhan G, Kutluhan S and Koyuncuoglu HR Is there any change of stroke incidence during Ramadan? Acta Neurol Scand 2000, I0I(4):259-6I

7. Temizhan A Is there any effect of Ramadan fasting on acute coronary heart disease events? Int J Cardiol I999, 70(2): I49-53

8. Akanji AO, Mojiminiyi OA and Abdella $N$ Beneficial changes in serum apo $A-I$ and its ratio to apo $B$ and $H D L$ in stable hyperlipidaemic subjects after Ramadan fasting in Kuwait Eur J Clin Nutr 2000, 54(6):508-13

9. Friedlander $Y$ Coronary heart disease risk factors among religious groupings in a Jewish population sample in Jerusalem Am J Clin Nutr 1985, 42(3):5 I I-2 I

10. Friedlander $Y$, Kark JD and Stein $Y$ Religious observance and plasma lipids and lipoproteins among 17-year-old Jewish residents of Jerusalem Prev Med 1987, I6(1):70-9

II. Fraser GE Associations between diet and cancer, ischemic heart disease, and all- cause mortality in non-Hispanic white California Seventh-day Adventists Am J Clin Nutr 1999, 70(3 Suppl):532S-538S 
12. Fraser GE Diet as primordial prevention in Seventh-Day Adventists Prev Med 1999, 29(6 Pt 2):SI8-23

13. Famodu AA Blood pressure and blood lipid levels among vegetarian, semi-vegetarian, and non-vegetarian native Africans Clin Biochem 1998, 3 I (7):545-9

14. Nieman DC Dietary status of Seventh-Day Adventist vegetarian and non-vegetarian elderly women J Am Diet Assoc 1989 89(12): 1763-9

15. Trichopoulou A Diet and overall survival in elderly people $B \mathrm{mj}$ 1995, 3 I I(70 I 8): 1457-60

16. Kafatos A Mediterranean diet of Crete: foods and nutrient content I Am Diet Assoc 2000, I 00(I 2): I 487-93

17. Lohman TG, Roche AF and Mastorell R Anthropometric standardization reference manual Champaign, IL: Human Kinetics Publishers 1991,

18. Allain CC Enzymatic determination of total serum cholesterol Clin Chem 1974, 20(4):470-5

19. Finley PR Cholesterol in high-density lipoprotein: use of $\mathbf{M g 2 +}$ dextran sulfate in its enzymic measurement Clin Chem 1978, 24(6):93I-3

20. Fossati $P$ and Prencipe $L$ Serum triglycerides determined colorimetrically with an enzyme that produces hydrogen peroxide Clin Chem I982, 28( 1 0):2077-80

21. Friedewald WT, Levy RI and Fredrickson DS Estimation of the concentration of low-density lipoprotein cholesterol in plasma, without use of the preparative ultracentrifuge Clin Chem 1972, I 8(6):499-502

22. Miller SA, Dykes DD and Polesky HF A simple salting out procedure for extracting DNA from human nucleated cells Nucleic Acids Res 1988, 16(3): 1215

23. Reymer PW Apolipoprotein E genotyping on agarose gels Clin Chem I995, 4 I(7): 1046-7

24. Ordovas JM The genetics of serum lipid responsiveness to dietary interventions Proc Nutr Soc 1999, 58(I): I7I-87

25. Dreon DM and Krauss RM Diet-gene interactions in human lipoprotein metabolism / Am Coll Nutr 1997, 16(4):3 I3-24

26. Lopez-Miranda J Effect of apolipoprotein E phenotype on dietinduced lowering of plasma low density lipoprotein cholesterol / Lipid Res 1994, 35(I I): 1965-75

27. Miettinen TA, Gylling $\mathrm{H}$ and Vanhanen $\mathrm{H}$ Serum cholesterol response to dietary cholesterol and apoprotein $E$ phenotype Lancet 1988, 2(8622): |26|

28. Masarei JR Vegetarian diets, lipids and cardiovascular risk Aust N Z J Med 1984, I4(4):400-4

29. Masarei JR Effects of a lacto-ovo vegetarian diet on serum concentrations of cholesterol, triglyceride, HDL-C, HDL2-C, HDL3-C, apoprotein-B, and Lp(a) Am J Clin Nutr 1984, 40(3):468-78

30. Barnard ND Effectiveness of a low-fat vegetarian diet in altering serum lipids in healthy premenopausal women $\mathrm{Am}$ / Cardio 2000, 85(8):969-72

31. Asztalos B Differential response to low-fat diet between low and normal HDL-cholesterol subjects J Lipid Res 2000 $4|(3): 32|-8$

32. Nicholson AS Toward improved management of NIDDM: A randomized, controlled, pilot intervention using a lowfat, vegetarian diet Prev Med 1999, 29(2):87-91

33. Lee HY Serum fatty acid, lipid profile and dietary intake of Hong Kong Chinese omnivores and vegetarians Eur J Clin Nutr 2000, 54(10):768-73

34. Hoffmann I Giessen Wholesome Nutrition Study: relation between a health-conscious diet and blood lipids Eur J Clin Nutr 200I, 55( I0):887-95

35. Toohey ML Cardiovascular disease risk factors are lower in African-American vegans compared to lacto-ovo-vegetarians J Am Coll Nutr 1998, I7(5):425-34

36. Wang TD Efficacy of cholesterol levels and ratios in predicting future coronary heart disease in a Chinese population $\mathrm{Am} J$ Cardiol 200I, 88(7):737-43

37. Solymoss BC Relation of coronary artery disease in women < 60 years of age to the combined elevation of serum lipoprotein (a) and total cholesterol to high-density cholesterol ratio Am J Cardiol I993, 72( I 7): I I I5-9

38. Hong MK Usefulness of the total cholesterol to high-density lipoprotein cholesterol ratio in predicting angiographic coronary artery disease in women Am J Cardiol I991, 68(17): 1646-50
39. Price JF Influence of high-density lipoprotein cholesterol and rheological factors on the sex difference in cardiovascular disease J Cardiovasc Risk 2000, 7( I):49-56

40. Onat $A$, Sansoy $V$ and Uysal $O$ Waist circumference and waistto-hip ratio in Turkish adults: interrelation with other risk factors and association with cardiovascular disease Int J Cardiol 1999, 70(I):43-50

4I. Mansfield E, McPherson R and Koski KG Diet and waist-to-hip ratio: important predictors of lipoprotein levels in sedentary and active young men with no evidence of cardiovascular disease J Am Diet Assoc 1999, 99( I I): 1373-9

42. Perry AC Clinical predictability of the waist-to-hip ratio in assessment of cardiovascular disease risk factors in overweight, premenopausal women Am J Clin Nutr 1998, 68(5): I022-

43. Haddad EH Dietary intake and biochemical, hematologic, and immune status of vegans compared with nonvegetarians $A m$ J Clin Nutr 1999, 70(3 Suppl):586S-593S

44. Burr ML and Butland BK Heart disease in British vegetarians $A m$ J Clin Nutr 1988, 48(3 Suppl):830-2

45. Key TJ, Davey GK and Appleby PN Health benefits of a vegetarian diet Proc Nutr Soc 1999, 58(2):27I-5

46. Key $T$ and Davey $G$ Prevalence of obesity is low in people who do not eat meat $B m j$ 1996, 313(7060):816-7

47. De Lorenzo A Effects of weight loss on body composition and pulmonary function Respiration 1999, 66(5):407-12

48. el Ati J, Beji C and Danguir J Increased fat oxidation during Ramadan fasting in healthy women: an adaptative mechanism for body-weight maintenance Am J Clin Nutr 1995, 62(2):302-7

49. Verschuren WM, Boerma GJ and Kromhout D Total and HDLcholesterol in The Netherlands: 1987-1992. Levels and changes over time in relation to age, gender and educational level Int J Epidemiol 1994, 23(5):948-56

50. Hardarson $T$ The relationship between educational level and mortality. The Reykjavik Study J Intern Med 200I, 249(6):495502

51. Tedesco MA Educational level and hypertension: how socioeconomic differences condition health care J Hum Hypertens 200I, I5( I 0):727-3I

52. Law M Dietary fat and adult diseases and the implications for childhood nutrition: an epidemiologic approach $\mathrm{Am} J$ Clin Nutr 2000, 72(5 Suppl):|29|S-1296S

53. Shahar DR Seasonal variations in dietary intake affect the consistency of dietary assessment Eur J Epidemiol 200 I, I 7(2): 129-33

54. Kafatos A Heart disease risk-factor status and dietary changes in the Cretan population over the past 30 y: the Seven Countries Study Am J Clin Nutr 1997, 65(6): I 882-6

55. Panagiotakos DB The association of Mediterranean diet with lower risk of acute coronary syndromes in hypertensive subjects Int J Cardiol 2002, 82(2): I4I-7

56. Kris-Etherton P AHA Science Advisory: Lyon Diet Heart Study. Benefits of a Mediterranean-style, National Cholesterol Education Program/American Heart Association Step I Dietary Pattern on Cardiovascular Disease Circulation 200I, 103(13):1823-5

57. Trichopoulou A and Vasilopoulou E Mediterranean diet and longevity BrJ Nutr 2000, 84(Suppl 2):S205-9

58. Trichopoulou A Cancer and Mediterranean dietary traditions Cancer Epidemiol Biomarkers Prev 2000, 9(9):869-73

59. Chliaoutakis JE Greek christian orthodox ecclesiastical lifestyle: could it become a pattern of health-related behavior? Prev Med 2002, 34(4):428-35

\section{Pre-publication history}

The pre-publication history for this paper can be accessed here:

http://www.biomedcentral.com/1471-2458/3/16/prepub 